\title{
Investigating the proxy effect and the saliency principle in household based postal questionnaires
}

\author{
A Tennant, E M Badley, $M$ Sullivan
}

\begin{abstract}
Study objective-The aim was to investigate two possible sources of bias inherent in using a household based postal questionnaire, the "proxy effect", inaccurate reporting about characteristics of others, and the "saliency principle", reporting of only the most salient features. This is of importance in surveys concerned with screening the population to identify individuals with certain characteristics, and so possibly relying on one member of the household to reply on behalf of all others.
\end{abstract}

Design and setting-A two stage survey of disablement in the population was undertaken. A first phase postal questionnaire was sent to 25168 households in Calderdale, West Yorkshire, England, to ascertain the prevalence of physical disability and of troubles with the joints. The second phase comprised in depth interviews with a sample of individuals identified in the first phase as being disabled.

Respondents-A total of 21889 postal questionnaires were returned (87\%) representing households containing 42826 people aged 16 years and over. A disproportionately stratified random sample of 950 respondents reporting disablity was taken in the second phase. Of these 891 were still available, and 838 (94\%) were interviewed.

Measurements and main results-The postal questionnaire found that almost $29 \%$ of those who lived "alone" (without another adult) reported some level of disability, compared to only $10 \%$ of those who lived with others. The difference remained significant after standardisation. This apparent underreporting or "proxy effect" was present for reporting about disability overall, but not for severe disability (dependence on help of others), which suggests the operation of the "saliency principle". Reporting on joint troubles appeared to be affected by the proxy effect both for any joint problems, and when more than five joints were affected. Analysis of a small set of postal questionnaires from respondents who reported joint problems only at interview and where we could identify who had completed the postal questionnaire supports the hypothesis of a proxy effect; two thirds of the original postal questionnaires had been completed by a proxy. The results were further complicated by an interaction between reporting of disability and joint troubles: the greater the level of disability, the less likely the reporting of joint troubles.

Conclusions-The findings have general implications for studies involving postal household screening questionnaires, and raises additional concerns about those that are multitopic in content. In surveys of symptoms and minor disability, a proxy effect is likely to be operative. This effect is not apparent for obvious and long standing problems such as dependence on others for help. However the interaction between the reporting of disability and joint symptoms carries important implications for the development of multitopic postal screening questionnaires.

Household based postal questionnaires are often used as a way of screening the population to identify individuals with certain characteristics. Little is known about the dynamics of completion of such questionnaires, yet there appears to be a potential for bias if one person fills in the questionnaire for the whole household. A study of published reports, much of which is in the context of face to face interviews, identifies two related sources of possible bias; underreporting the symptoms of others in the same household, ${ }^{1-4}$ the "proxy effect", and accurate reporting of only the most salient features of the subject under investigation, ${ }^{5-6}$ the "saliency principle".

A further aspect is the potential interaction between any proxy effect in reporting and saliency. For example, does the likelihood of underreporting diminish as the seriousness of the attributes under investigation increase, or does overreporting become a problem? These potential biases seem to have attracted very little attention in the context of self completed questionnaires used at the household level. The acuracy of proxy reporting is difficult to evaluate as there is no immediately obvious population of underreporters, in contrast, for example, to the always evident population of non-responders.

A postal screening survey to households as the first stage of a study of disablement in the community has enabled us to look at these effects in more detail. This questionnaire collected data on all household members. In most instances it was completed by one person on behalf of all others, although we have no information on the degree of consultation that might have been involved. The questionnaire, which was concerned with the reporting of both disabilities and joint troubles, offered us the opportunity to 
study rates of reporting where respondents were living with and without other adults. We also were able to look at rates of reporting of different levels of severity of disability and where joint troubles were also present.

We hypothesised that: (a) should a proxy effect exist we would find higher prevalence estimates for disablement and joint troubles from those who live alone, as opposed to those who live with significant others; and (b) that should the saliency principle apply we would expect that the more serious the problem, the more likely it is to be reported.

\section{Methods}

A survey was carried out in a population in Calderdale in West Yorkshire, England, with three major sets of objectives; (1) to gain information to help plan services for those aged 16-64 years who were at the margins of institutional care; (2) to study the distribution of joint troubles in the population; and (3) to investigate the nature of rheumatic disablement in the population. ${ }^{7} \mathrm{~A}$ two stage methodology was employed, similar to that used in other surveys of disablement in the population. ${ }^{8}$ The first stage consisted of a postal questionnaire to every third household in the area, using the Domestic Rating List as the sampling frame. The sample size was determined by the need to provide meaningful analysis for a rare group in the population, namely those very severely physically disabled aged 16-64 years, based on an estimate by Harris of 12 per 10000 people. $^{9}$

The four page screening questionnaire used in phase 1 elicited demographic characteristics of the household, and information about individuals within the household who experienced disability, in terms of difficulties or dependence in selected activities of daily living. Dependence was defined

Table I Age and sex structure of the total survey population and number and proportion who live alone.

\begin{tabular}{|c|c|c|c|c|c|c|c|c|c|}
\hline \multirow[b]{2}{*}{$\begin{array}{l}\text { Age group } \\
\text { (years) }\end{array}$} & \multicolumn{3}{|c|}{ All persons } & \multicolumn{3}{|l|}{ Males } & \multirow{2}{*}{$\frac{\text { Females }}{\text { Total }}$} & \multirow{2}{*}{\multicolumn{2}{|c|}{ Lives alone }} \\
\hline & $\begin{array}{l}\text { Total } \\
n\end{array}$ & \multicolumn{2}{|c|}{ Lives alone } & $\begin{array}{l}\text { Total } \\
n\end{array}$ & \multicolumn{2}{|c|}{ Lives alone } & & & \\
\hline $\begin{array}{l}16-34 \\
35-54 \\
55-64 \\
65-74 \\
\geqslant 75\end{array}$ & $\begin{array}{r}14577 \\
13175 \\
5967 \\
5441 \\
3666\end{array}$ & $\begin{array}{r}951 \\
953 \\
883 \\
1502 \\
1899\end{array}$ & $\begin{array}{r}(6 \cdot 5) \\
(7 \cdot 2) \\
(14 \cdot 8) \\
(27 \cdot 6) \\
(51 \cdot 8)\end{array}$ & $\begin{array}{l}7244 \\
6592 \\
2776 \\
2398 \\
1221\end{array}$ & $\begin{array}{l}376 \\
459 \\
272 \\
386 \\
365\end{array}$ & $\begin{array}{c}(5 \cdot 2) \\
(7 \cdot 0) \\
(9 \cdot 8) \\
(16 \cdot 1) \\
(29 \cdot 9)\end{array}$ & $\begin{array}{l}7333 \\
6583 \\
3191 \\
3043 \\
2445\end{array}$ & $\begin{array}{r}575 \\
494 \\
611 \\
1116 \\
1534\end{array}$ & $\begin{array}{l}(7 \cdot 8) \\
(7.5) \\
(19 \cdot 1) \\
(36.7) \\
(62.7)\end{array}$ \\
\hline Total & 42826 & 6188 & $(14 \cdot 4)$ & 20231 & 1858 & $(9 \cdot 2)$ & 22595 & 4330 & $(19 \cdot 2)$ \\
\hline
\end{tabular}

Table II Proportion of respondents living alone and with others with disability in selected activities of daily living, by age and sex, with $95^{\circ}{ }_{0}$ confidence intervals (CI).

\begin{tabular}{|c|c|c|c|c|c|}
\hline \multirow[b]{3}{*}{ Age (years) } & \multirow[b]{3}{*}{ Sex } & \multicolumn{4}{|c|}{ Living circumstances } \\
\hline & & \multicolumn{2}{|l|}{ Alone } & \multicolumn{2}{|l|}{ With others } \\
\hline & & Proportion & $95^{\circ}{ }_{0} C I$ & Proportion & $95^{\circ}{ }_{0} C I$ \\
\hline \multirow{2}{*}{$16-34$} & f & 0.040 & $0.024-0.056$ & 0.014 & $0.011-0.017$ \\
\hline & $\mathrm{m}$ & $0 \cdot 032$ & $0.014-0.050$ & 0.016 & $0.013-0.019$ \\
\hline \multirow[t]{2}{*}{$35-54$} & f & $0 \cdot 141$ & $0.110-0.172$ & 0.060 & $0.054-0.066$ \\
\hline & $\mathrm{m}$ & $0 \cdot 105$ & $0.077-0.133$ & 0.052 & $0.046-0.058$ \\
\hline \multirow[t]{2}{*}{$55-64$} & f & $0 \cdot 231$ & $0 \cdot 198-0 \cdot 264$ & $0 \cdot 193$ & $0 \cdot 178-0 \cdot 208$ \\
\hline & $\mathrm{m}$ & $0 \cdot 221$ & $0.171-0.270$ & $0 \cdot 165$ & $0.150-0.179$ \\
\hline \multirow{2}{*}{$65-74$} & f & 0.320 & $0.294-0.344$ & $0 \cdot 302$ & $0.281-0.322$ \\
\hline & $\mathrm{m}$ & $0 \cdot 246$ & $0.203-0.289$ & 0.247 & $0.228-0.266$ \\
\hline \multirow[t]{2}{*}{$75+$} & f & 0.551 & $0.526-0.576$ & 0.542 & $0.510-0.575$ \\
\hline & $\mathrm{m}$ & $0 \cdot 375$ & $0.325-0.425$ & 0.345 & $0.313-0.376$ \\
\hline \multirow{2}{*}{\multicolumn{2}{|c|}{$\begin{array}{l}\text { Total (crude rate) } \\
\text { (standardised rate) }\end{array}$}} & $0 \cdot 289$ & $0 \cdot 278-0 \cdot 300$ & $0 \cdot 100$ & $0.097-0.103$ \\
\hline & & $0 \cdot 159$ & $0 \cdot 148-0 \cdot 169$ & 0.122 & $0.118-0.126$ \\
\hline
\end{tabular}

as requiring help to get in or out of bed, with dressing, to get to and use the toilet, or to get out of the house. The questionnaire also asked about persons in the household who experienced joint troubles-pain, swelling, or stiffness in the joints, neck or back. For each person with such troubles, the site of the affected joint was determined, as well as an indication of the underlying condition.

The second stage was an in depth personal interview with a stratified random sample of those ascertained to be disabled in phase 1 of the survey. This paper is primarily concerned with results from the first phase of the survey.

Questionnaires were sent to 25168 occupied dwellings in Calderdale and 21889 were returned, a response rate of $87^{\circ}{ }_{0}$. This was achieved by the original post (1st wave, $57^{\circ} \mathrm{o}$ response), two further postal follow ups (2nd and $3 \mathrm{rd}$ waves, taking the response to $73^{\circ}{ }_{\mathrm{o}}$ and $81^{\circ}$ o respectively), the latter including a small personal call back, and a final postal follow up (the 4th wave).

In order to look for a "proxy effect" we divided respondents into two groups, those who lived without any other person aged 16 years and over (referred to as the "alone" group), and those who lived with others (referred to as the "with others" group). Investigating a proxy effect in this manner assumes that no one under the age of 16 years filled in the questionnaire on behalf of the household. The "alone" group includes 588 single parent households with children under 16 years.

Individual age-sex specific estimates were calculated for those with (a) any disability and (b) with dependency in activities of daily living, (c) any joint troubles, and (d) with joint troubles at five or more sites. Risk ratios ${ }^{10}$ were calculated to compare those who lived alone to those living with others. Direct standardisation ${ }^{11}$ with calculation of appropriate confidence intervals ${ }^{12}$ was applied to the overall total rates, to allow for differences because of the different age-sex structure of the population of those living alone compared to those living with others.

\section{Results}

The age and sex structure of the survey population is shown in table $I$, together with the number and proportion in each age group who live alone. Overall $14^{\circ}{ }_{0}$ of the population lived with no other adults. The proportion is higher for females in each age group, being over twice that for males in those over the age of 65 years.

Table II shows that a proportion of $0 \cdot 289$, or $28.9^{\circ}{ }_{0}$ of those living alone, reported some level of disability, compared to only $10 \cdot 0^{\circ}{ }_{0}$ of those living with others. The risk ratio for those living alone, compared to those living with others is 2.9 , based on the crude rates. This represents a significantly lower prevalence of disablement for those who live with others, as indicated by the nonoverlapping $95^{\circ}$, confidence intervals. Age-sex specific rates were significantly lower for females aged 16-34 and 35-54 years, and for males aged 35-54 years, who lived with others. Standardisation reduced the risk ratio to $1 \cdot 3$, but it still represents a significant difference in prevalence between the two groups. 
A similar picture was found for those who reported joint troubles. Table III shows that $38.6 \%$ of those living alone reported joint troubles, compared to $21.4 \%$ of those living with others. Both females and males aged 16-34 years showed significant differences, as well as females aged 35-54 and 75 years and over. The risk ratio of 1.8 was reduced to 1.2 after standardisation for age and sex, but the difference remained significant.

Table III Proportion of respondents living alone and with others with any level of joint trouble, by age and sex, with $95 \%$ confidence intervals (CI).

\begin{tabular}{|c|c|c|c|c|c|}
\hline \multirow[b]{3}{*}{ Age (years) } & \multirow[b]{3}{*}{ Sex } & \multicolumn{4}{|c|}{ Living circumstances } \\
\hline & & \multicolumn{2}{|l|}{ Alone } & \multicolumn{2}{|l|}{ With others } \\
\hline & & Proportion & $95 \% \mathrm{CI}$ & Proportion & $95 \% \mathrm{CI}$ \\
\hline $16-34$ & $f$ & $0 \cdot 146$ & $0.117-0.175$ & 0.079 & $0.073-0.086$ \\
\hline $35-54$ & $\mathrm{~m}$ & $0 \cdot 141$ & $0 \cdot 106-0 \cdot 176$ & 0.066 & $0.060-0.071$ \\
\hline $35-54$ & f & $0 \cdot 310$ & $0.269-0.350$ & 0.249 & $0.238-0.260$ \\
\hline $55-64$ & $\underset{f}{m}$ & $\begin{array}{r}0 \cdot 227 \\
0.435\end{array}$ & $0 \cdot 188-0.265$ & 0.202 & $0 \cdot 192-0 \cdot 212$ \\
\hline & $\begin{array}{l}\mathrm{I} \\
\mathrm{m}\end{array}$ & $\begin{array}{l}0.435 \\
0.327\end{array}$ & $\begin{array}{l}0.396-0.475 \\
0.271-0.383\end{array}$ & $\begin{array}{l}0.390 \\
0.345\end{array}$ & $\begin{array}{l}0.371-0.409 \\
0.326-0.363\end{array}$ \\
\hline $65-74$ & $\mathrm{f}$ & 0.461 & $0.431-0.490$ & 0.417 & $0.395-0.439$ \\
\hline & $\mathrm{m}$ & 0.350 & $0.302-0.397$ & 0.350 & $0.330-0.371$ \\
\hline $75+$ & f & 0.559 & $0.534-0.584$ & 0.485 & $0.453-0.518$ \\
\hline & & 0.370 & $0.320-0.419$ & 0.324 & $0.292-0.355$ \\
\hline \multicolumn{2}{|c|}{$\begin{array}{l}\text { Total (crude rate) } \\
\text { (standardised rate) }\end{array}$} & $\begin{array}{l}0 \cdot 386 \\
0 \cdot 278\end{array}$ & $\begin{array}{l}0.374-0.399 \\
0.263-0.293\end{array}$ & $\begin{array}{l}0.214 \\
0.229\end{array}$ & $\begin{array}{l}0.210-0.218 \\
0.224-0.235\end{array}$ \\
\hline
\end{tabular}

Table IV Proportion of respondents living alone and with others with dependence in selected activities of daily living, by age and sex, with $95 \%$ confidence intervals (CI).

\begin{tabular}{|c|c|c|c|c|c|}
\hline \multirow[b]{3}{*}{ Age (years) } & \multirow[b]{3}{*}{ Sex } & \multicolumn{4}{|c|}{ Living circumstances } \\
\hline & & \multicolumn{2}{|l|}{ Alone } & \multicolumn{2}{|l|}{ With others } \\
\hline & & Proportion 9 & $95 \% C I$ & Proportion & $95 \% C I$ \\
\hline \multirow{2}{*}{ 16-34 } & f & 0.010 & $0.002-0.019$ & 0.003 & $0.002-0.004$ \\
\hline & $\mathrm{m}$ & 0.008 & $-0.001-0.017$ & 0.004 & $0.003-0.006$ \\
\hline \multirow{2}{*}{$35-54$} & f & 0.036 & $0.020-0.053$ & 0.014 & $0.011-0.017$ \\
\hline & $\mathrm{m}$ & 0.004 & $-0.002-0.010$ & 0.009 & $0.007-0.012$ \\
\hline \multirow{2}{*}{$55-64$} & f & 0.033 & $0.019-0.047$ & 0.045 & $0.037-0.053$ \\
\hline & m & 0.026 & $0.007-0.045$ & 0.026 & $0.020-0.032$ \\
\hline \multirow{2}{*}{$65-74$} & f & 0.061 & $0.047-0.075$ & 0.085 & $0.073-0.098$ \\
\hline & m & 0.047 & $0.026-0.068$ & 0.058 & $0.047-0.068$ \\
\hline \multirow[t]{2}{*}{$75+$} & f & $0 \cdot 258$ & $0 \cdot 236-0 \cdot 280$ & 0.306 & $0.276-0.336$ \\
\hline & $\mathrm{m}$ & 0.112 & $0 \cdot 080-0.145$ & $0 \cdot 141$ & $0 \cdot 118-0 \cdot 165$ \\
\hline \multicolumn{2}{|c|}{$\begin{array}{l}\text { Total (crude rate) } \\
\text { (standardised rate) }\end{array}$} & $\begin{array}{l}0.094 \\
0.038\end{array}$ & $\begin{array}{l}0.086-0.101 \\
0.034-0.043\end{array}$ & $\begin{array}{l}0.029 \\
0.040\end{array}$ & $\begin{array}{l}0.027-0.031 \\
0.038-0.043\end{array}$ \\
\hline
\end{tabular}

Table $V$ Proportion of respondents living alone and with others with troubles in $5+$ joints, by age and sex, with $95 \%$ confidence intervals (CI).

\begin{tabular}{|c|c|c|c|c|c|}
\hline \multirow[b]{3}{*}{ Age (years) } & \multirow[b]{3}{*}{ Sex } & \multicolumn{4}{|c|}{ Living circumstances } \\
\hline & & \multicolumn{2}{|l|}{ Alone } & \multicolumn{2}{|l|}{ With others } \\
\hline & & Proportion & $95 \% C I$ & Proportion & $95^{\circ} \mathrm{CI}$ \\
\hline $16-34$ & f & 0.017 & $0.007-0.028$ & 0.009 & $0.007-0.012$ \\
\hline \multirow{2}{*}{$35-54$} & $m$ & 0.024 & $0.008-0.039$ & 0.006 & $0.004-0.008$ \\
\hline & $\begin{array}{l}\text { f } \\
\text { m }\end{array}$ & $\begin{array}{l}0.093 \\
0.046\end{array}$ & $0.067-0.119$ & 0.057 & $0.051-0.063$ \\
\hline \multirow{2}{*}{$55-64$} & $\mathrm{f}$ & $\begin{array}{l}0.040 \\
0.129\end{array}$ & $\begin{array}{l}0.027-0.065 \\
0.103-0.156\end{array}$ & 0.029 & $\begin{array}{l}0.025-0.033 \\
0.099-0.123\end{array}$ \\
\hline & $\mathrm{m}$ & 0.088 & $0.055-0.122$ & 0.073 & $0.063-0.083$ \\
\hline \multirow{2}{*}{$65-74$} & f & $0 \cdot 127$ & $0 \cdot 108-0.147$ & $0 \cdot 119$ & $0 \cdot 105-0 \cdot 134$ \\
\hline & $\mathbf{m}$ & 0.052 & $0.030-0.074$ & 0.061 & $0.051-0.072$ \\
\hline \multirow[t]{2}{*}{$75+$} & f & $0 \cdot 167$ & $0 \cdot 148-0 \cdot 186$ & $0 \cdot 114$ & $0.094-0.135$ \\
\hline & m & 0.074 & $0.047-0.101$ & 0.062 & $0.046-0.078$ \\
\hline \multirow{2}{*}{\multicolumn{2}{|c|}{$\begin{array}{l}\text { Total (crude rate) } \\
\text { (standardised rate) }\end{array}$}} & $0 \cdot 102$ & $0.095-0.110$ & 0.044 & $0.042-0.046$ \\
\hline & & 0.067 & $0.060-0.074$ & 0.049 & $0.046-0.051$ \\
\hline
\end{tabular}

Table VI Comparison of responses about joint troubles between the postal questionnaire and interview phases for respondents in the interview sample (McNemar's test for matched samples).

\begin{tabular}{|c|c|c|c|c|c|}
\hline \multirow{2}{*}{$\begin{array}{l}\text { Response in phase } 1 \\
\text { sift questionnaire }\end{array}$} & & \multicolumn{3}{|c|}{ Response in phase 2 interview } & \\
\hline & & Yes & No & Total & \\
\hline All respondents in sample & $\begin{array}{l}\text { Yes } \\
\text { No }\end{array}$ & $\begin{array}{r}667 \\
95\end{array}$ & $\begin{array}{l}33 \\
43\end{array}$ & $\begin{array}{l}700 \\
138\end{array}$ & $\chi^{2}=29.07 p<0.001$ \\
\hline $\begin{array}{l}\text { Living circumstances } \\
\text { - alone } \\
\text { - with others }\end{array}$ & $\begin{array}{l}\text { Yes } \\
\text { No } \\
\text { Yes } \\
\text { No }\end{array}$ & $\begin{array}{r}175 \\
15 \\
484 \\
80\end{array}$ & $\begin{array}{r}9 \\
6 \\
24 \\
35\end{array}$ & $\begin{array}{r}184 \\
21 \\
508 \\
115\end{array}$ & $\begin{array}{l}\chi^{2}=1.50 \mathrm{NS} \\
\chi^{2}=29.08 \mathrm{p}<0.001\end{array}$ \\
\hline
\end{tabular}

Should the saliency principle be operative, the difference in rate of reporting between the two groups should be less for more serious disablement and joint trouble. Table IV shows a significant difference in crude rate of reporting of dependence between the two groups, with a risk ratio of 3.2. However this fell to 0.95 after standardisation, and this difference is not significant.

Table $\mathrm{V}$ shows the prevalence of serious joint involvement, defined as pain, swelling, or stiffness at five or more joint sites. The reported prevalence was higher for females than males except in the 16-34 year age group. The reported prevalence for those living alone was over twice that for those living with others. After standardisation the risk ratio was reduced to 1.4 which is still a significant difference.

An advantage of a two phase survey is the availability of further information about a subset of those responding at phase 1 . There was a significant increase in the number of respondents reporting joint troubles when interviewed at phase 2 compared with the reported response to the phase 1 questionnaire (table VI). If the proxy effect were operating at phase 1 , this change should occur preferentially where respondents lived with others. This is confirmed by the data, where there is no significant difference in reported joint troubles for those living alone, but a significant change for those living with others.

Further examination of the 80 respondents who lived with others and who reported troubles only at the phase 2 interview showed that in the 54 cases where we could identify who had completed the sift questionnaire, two thirds had been completed by proxy. Eighteen respondents had completed the questionnaire themselves and subsequently at interview reported troubles with joints when they had not done so at the phase 1 questionnaire. It is not possible to tell with such low numbers whether this represents real change in experience of joint symptoms (the average time between returning the phase 1 sift and the second phase interview was 3 months), a change because the interview looked at joint troubles in more detail, or simply self underreporting at phase 1 .

For those living with others there was also a clear indication of association between the level of disability reported at phase 2 and the likelihood of reported joint symptoms at phase 1 . The higher the level of disability the greater the likelihood of change from a report of no joint troubles at phase 1 to joint troubles at phase 2 . Thus for those living with others the change from no to yes was $11^{\circ}$ of those dependent at the less than daily level, ${ }^{7} 12^{\circ} \%$ of those daily dependent, and $29 \%$ of those needing continuous supervision and/or care.

Inspection of the questionnaires showed that this "disability related" effect was occurring when the questionnaire was completed by proxy. Thus part of the "proxy effect" we have identified may have been caused by an "overshadowing" effect of disability. The greater the level of disability, the less likely were joint troubles to be reported at phase 1 , implying that whoever was filling in the questionnaire was giving greater importance to the level of disability than to reporting on troubles with joints (which may or may not have been associated with the disability). 
Finally we tested to see if there was any link between the proxy effect and the likelihood of responding at different waves of the postal survey. As the survey progressed little difference was found in the cumulative proportion of the two types of households, implying that this would be maintained among non-responders. ${ }^{13}$ Thus differential non-response between the "alone" and "with others" groups would seem unlikely as a source of bias. We also examined the likelihood of bias arising from the possibility that late respondents were less diligent in the completion of their questionnaires and more likely to exhibit a proxy effect. Using serious joint troubles as the basis for testing for a wave effect, we found no evidence to support this. Standardised rates comparing those living alone with those living with others were significantly different at the first and third waves, but not at the second and fourth waves.

\section{Discussion}

Our study shows some differences in levels of reported disability and joint troubles between those who live alone and those who live with others. There are good reasons why this should be. The age-sex structure of the populations for the two groups are quite different with, for example, an excess of elderly females among those living alone. With morbidity among females consistently reported as greater than males ${ }^{1415}$ and greater with age ${ }^{716}$ it is hardly surprising that overall rates of reporting of disability and joint symptoms are higher in those living alone. When the results are standardised to take account of age and sex structure, the differences are much less pronounced, but nevertheless in most cases compatible with a proxy effect.

A proxy effect was found for reporting of any level of disability, but was not apparent for those who were disabled to such an extent that they were dependent on others, which suggests that the saliency principle has operated in the survey with respect to disability. It is likely that a household informant would be aware of the need for help of others; this may not be so when just difficulties rather than dependence in daily activities were experienced. A proxy effect is seen for the reporting of joint troubles, which is not mitigated by the saliency principle for troubles with five or more joints. It may be that joint troubles are less apparent to other household members, or that such complaints are disregarded. There was some evidence, however, that some of this underreporting occurred for those who were considerably disabled, suggesting the fact that disability overshadowed the reporting of joint troubles.

The possibility of incorrect reporting by one member of the household about key characteristics of other members poses a threat to the validity of information gained by postal questionnaires which are household based. The literature concerning face to face interviews, as well as postal questionnaires, gives some credence to the "proxy effect". What form it takes is less clear. Where experiments have been carried out with face to face interviews to test the differences in reporting family status and other characteristics, results have shown that differences occur according to which family member is interviewed. ${ }^{17} 18$ There is some evidence to suggest that male heads of households are particularly poor at reporting symptoms of others in their household. ${ }^{17} \mathrm{~A}$ lower level of symptom reporting when reporting about others has been observed. It has been postulated that if a respondent reporting about the health of another household member is limited by his or her own knowledge, then regardless of the skill of the interviewer, if the respondent is uncertain, then they will fail to report the symptom. ${ }^{3}$ In a study of 2768 members of the League of Women Voters in the USA, Donald ${ }^{19}$ found that item non-response on the self completed questionnaire was greater about estimates of the behaviour of others. This led him also to suggest that respondents required greater certainty before making a specific judgement about another person.

Differences have also been found between reported health symptoms and information held on medical records. ${ }^{20}$ Warren, ${ }^{21}$ looking at the difference between survey findings and agency records, found that $10^{\circ}{ }_{0}$ of households who had returned a negative reply did contain a person with a significant degree of impairment. Maclean and Genn ${ }^{6}$ estimated a loss of $18^{\circ}{ }_{0}$ of positive cases in their postal study, something they considered acceptable in lieu of the drastically reduced costs of the method. While most of the examples of the proxy effect relate to underreporting of characteristics, there has occasionally been evidence to suggest overreporting by proxies, ${ }^{22}$ or overestimation of patients' disabilities. ${ }^{23}$

One study involving a postal follow up of the victims of domestic accidents found the misfortunes of those aged 60 years and over to be well reported. ${ }^{6}$ The authors suggest that this may have been due to the fact that the kinds of functional limitations being described were long standing and probably permanent. An interview based study of male freshman college students also found that serious disorders which required repeated attention were more salient than less serious ones, and were more likely to be reported accurately. ${ }^{5}$ This led to the suggestion that all studies support the general principle that accurate reporting occurs when the illness in question is salient, and social and psychological barriers to reporting are absent.

Our findings imply that in household based postal questionnaire surveys of symptoms and minor disability, a proxy effect is likely to be operative. This effect is not apparent for obvious and longstanding problems such as dependence on others for help, which was the primary focus of our study. However, the "overshadowing effect" that disability appeared to have over the reporting of joint symptoms carries important implications for the development of multitopic postal screening questionnaires, even when those topics, as with disability and joint troubles in our questionnaire, may be expected to be correlated. This might have considerable impact on both ascertainment and prevalence estimates.

The importance of being able to monitor for a proxy effect, and any overshadowing effect in a multitopic questionnaire, cannot be understated. 
1 Kovar MG, Wright RA. An experiment with alternative respondent rule in the National Health Interview Survey. Proc Am Stat Assoc 1973; statistical section: 311-7.

2 Krueger DE. Measurement of prevalence of chronic disease by household interviews and clinical evaluations. $A m \mathcal{F}$ Public Health 1957; 47: 953-60.

3 Nisselson $\mathrm{H}$, Woolsey TD. Some problems of the household interview design for the National Health Survey. $\mathcal{7} \mathrm{Am}$ Stat Assoc 1959; 54: 69-87.

4 O'Toole BI, Battistutta D, Long A, Crouch K. A comparison of costs and data quality of three health survey methods: mail, telephone and personal home interview. $\mathrm{Am}$ f Epidemiol 1986; 124: 317-28.

5 Mechanic D, Newton $M$. Some problems in the analysis of morbidity data. $f$ Chron Dis $1965 ; 18$ : 569-80.

6 Maclean M, Genn H. Methodological issues in social surveys. London: Macmillan, 197

7 Badley EM, Tennant A. Calderdale health and disablement survey. Manchester: Arthritis and Rheumatism Council for Research, 1988.

8 Knight R, Warren M. Physically disabled people living at home: a study of numbers and needs. London: HMSO, 1978.

Harris AI, Head E. Sample surveys in local authority areas. London: OPCS.

10 Feinstein AR. Clinical epidemiology. The architecture of clinical research. Philadelphia: WB Saunders, 1985.

$11 \mathrm{Hill}$ AB. Statistical methods in clinical and preventive medicine. Edinburgh: Livingstone, 1962.

12 Norris JA, GArdner MJ. Calculating confidence intervals for relative risk (odds ratios) and standardised ratios and for relative risk (odds ratios)
rates. $B M$ F $1988 ; 296$ : 1313-6.

13 Tennant A, Badley EM. A confidence interval approach to investigating non-response bias and monitoring response to postal questionnaires. F Epidemiol Community Health 1991; 45: 81-5.

14 Nathanson CA. Sex roles as variables in the interpretation of morbidity data: a methodological critique. Int $\mathcal{f}$ Epidemiol 1978; 7: 253-62.

15 Marcus AC, Seeman TE. Sex differences in reports of illness and disability: a preliminary test of the "fixed role obligations" hypothesis. I Health Soc Behav 1981; 22: 174-82.

16 Martin J, White A. The prevalence of disability among adults. OPCS surveys of disability in Great Britain, Report adults. OPCS surveys of disability in Great Britain, Report

17 Cartwright A. The effect of obtaining information from different informants on a family morbidity inquiry. Appl different informants
Stat 1957; 6: 18-25.

18 Ferber R. On the reliability of responses secured in sample surveys. F Am Stat Assoc 1955; 50: 788-810.

19 Donald MN. Implications of non-response for the interpretation of mail questionnaire data. Public Opinion $Q$ 1960; 24: 99-114.

20 Thompson DJ, Tauber J. Household survey individual interview, and clinical examination to determine prevalence of heart disease. Am F Public Health 1957; 47: 1131-40.

21 Warren MD. Handicapped people in the community: a survey of agencies records in Canterbury. Canterbury: Health Services Research Unit (Report No 19), University of Kent, 1975.

22 Briscoe ME. Proxy responses in health surveys: a methodological issue. Soc Health Illness 1984; 6: 359-65.

23 Magaziner J, Simonsick EM, Kashner M, Hebel JR. Patient-proxy response comparability on measure of Patient-proxy response comparability on measure of
patient health and functional status. $\mathcal{F}$ Clin Epidemiol 1988; 41: $1065-74$. 